\title{
Out of Hours
}

\section{Exception reporting as a quality marker}

'GPS who practise patient-centred, evidence-based care will, inevitably, have higher exception rates. As outliers, they should expect a visit from their PCT hit squad.'

I made this prediction at the end of a lecture on Communicating Risk to Patients, delivered at our Faculty Annual Symposium on a sunny summer morning in 2005, just over a year after the introduction of the Quality and Outcomes Framework (QOF). So it was not a surprise but rather a source of satisfaction when my practice received just such a visit 5 years later. The visiting team included a GP who was also a medical adviser to the PCT and whom I respected. The conduct of the visiting team was impeccable and professional. The members gave the impression of having open minds and listened attentively to the reasons for excepting the individuals they had singled out. They courteously pointed out alternatives to exception in two cases but as for the rest, they accepted that we had good reasons. So how did we, a training practice with enviable performance indicators in such matters as prescribing, find ourselves at the business end of an investigation? I like to think of the affair as a marker of quality practice. To understand, first look at what patients want and what they would do if they were to get it.

A report prepared for the Institute of Medicine, in the US, found that while eight out of 10 people want their practitioner to listen to them, only six out of 10 say it actually happens. Nine out of 10 people want their providers to work with them as a team, but just four out of 10 say it actually happens. ${ }^{1}$ So what is going on in consultations? The conclusion can only be that the doctor knows best principle survives. Unless British physicians are radically different from their North American counterparts, it is very unlikely that patients over here are involved in many decisions. And in the absence of evidence to the contrary, this must also apply to consultations for chronic disease management.

So what would patients do if we truly involved them in decisions on the initiation of drugs that thicken the bones or thin the blood? If they had the full facts, would they be as willing to take drugs that decrease blood pressure and increase QOF points? Research so far suggests otherwise.

The threshold at which patients choose to accept an intervention has been shown to be higher than that which practitioners would recommend it; this has been shown for hypertension, cancer, obstetrics and gynaecology, and acute respiratory illness. ${ }^{2}$

It would be hard to find a doctor today who does not believe that they should consider patient values and preferences. It is a pillar of evidence-based practice but by no means confined to it. Yet what is practised is evidence-driven medicine. Practitioners push interventions shown to be effective usually without involving patients and often without stopping to consider if the effect is worth it. This has been demonstrated in heart failure ${ }^{3}$ but my patients' experiences in diverse clinics shows it is widespread. In the belief that patients are being informed, doctors tend to give the positive aspects of an intervention more than the drawbacks. It is a little ironic that of the doctors who elicit patient preferences and discuss the disadvantages of an intervention most are not GPs but surgeons, at least in the US.'

Communicating effectively and ethically with patients is not just about what is said but how it is said. The principles of communicating risk are the same as the principles of good consultations: ${ }^{4}$

\section{Listen to the patient.}

2. Use language that patients can understand, such as frequencies lone in 10 rather than $10 \%)$.

3. Be honest, for example, give absolute

\section{ADDRESS FOR CORRESPONDENCE}

\section{Kevork Hopayian}

The Surgery, Main Street, Leiston Road, IP16 4ES, UK.

\section{E-mail: k.hopayianabtinternet.com}

risks rather than relative risks when the latter can exaggerate the perceived benefit.

4. Stop and check that the patient has understood.

The more you do this, the more your patients will choose not to accept the things that QOF rewards. In the bureaucratic returns they are listed as dissenters. The choice of this term brands them as rebels against medical orthodoxy rather than individuals exercising their rights. To me, warranted exceptions are the consequence of patient-centred care, an indication of evidence based not driven medicine, a mark of quality practice. I doubt very much that they would ever attract their own QOF points.

\section{Kevork Hopayian,}

GP, Leiston Surgery, Suffolk; Honorary Senior Lecturer, Norwich Medical School; Primary Care Tutor, Health Education, East of England.

\section{DOI: 10.3399/bjgp13X668276}

\section{REFERENCES}

1. Alston $C L$, Paget GC, Halvorson B, et al. Communicating with patients on health care evidence. Discussion Paper. Washington, DC: Institute of Medicine, 2012

2. Montgomery AA, Fahey T. How do patients' treatment preferences compare with those of clinicians? Qual Health Care 2001; 10lSuppl 1): i39-43.

3. Sanders T, Harrison S, Checkland K. Evidence-based medicine and patient choice: the case of heart failure care. J Health Serv Res Policy 2008; 13(2): 103-108.

4. Australian Government National Health and Medical Research Council. Making decisions about tests and treatments: principles for better communication between healthcare consumers and healthcare professionals. Canberra: Australian Government National Health and Medical Research Council, 2005. 